\title{
Los límites constitucionales y legales del endeudamiento provincial
}

\section{Introducción}

Américo José Demaría

Profesor adjunto ordinario de las cátedras Administración Pública y

Gestión y Políticas Públicas de la Facultad de Ciencias Económicas de la Universidad Nacional del Litoral. E-mail: americodemaria@hotmail.com
En reiteradas oportunidades y por diversas circunstancias, este tema mereció diversos trabajos por parte del autor. Ahora ante la instancia de la sanción legislativa por parte de la Provincia de la denominada "Ley de Administración, Eficiencia y Control" que lleva el número 12.510 , se vuelve a discurrir sobre esta particular situación de establecer los límites al endeudamiento provincial.

La Constitución de la Provincia de Santa Fe establece, en su texto vigente, límites al endeudamiento provincial.

Taxativamente en el Capítulo IV "Atribuciones del Poder Legislativo", el artículo $55^{\circ}$ establece:

\section{"Corresponde a la Legislatura:}

$12^{\circ}$ - Autorizar al Poder Ejecutivo para celebrar contratos y aprobar o desechar los concluidos "ad-referendum"de la Legislatura. El servicio de la totalidad de las deudas provenientes de emprestitos no puede comprometer más de la cuarta parte de la renta provincial;"

A partir de esta limitante, de confusa redacción y subjetiva interpretación, se pretenderá analizar un conjunto de componentes para discernir su implicancia y verificar el modo en que la legislación reglamentaria sobre el particular le otorga a la temática.

Para ello el trabajo se descompone en cuatro cuerpos: el primero rastrea los antecedentes constitucionales provinciales con el objeto de vislumbrar el espíritu que siguieron los constituyentes en la inserción del inciso mencionado. 
Seguidamente abordaremos los principios doctrinarios para efectuar las comparaciones oportunas entre distintos juristas en la materia. La acepción de los términos incluidos en el precepto constitucional será definitoria a la hora de determinar la real interpretación de la norma.

Luego encararemos la reglamentación del texto con el objeto de evitar las interpretaciones forzadas que del mismo se efectúan.

Y por último efectuaremos un análisis en función de la sanción nacional de una norma que se contrapone a la legislación provincial.

\section{Antecedentes constitucionales}

La primera de las cartas constitucionales dada por un cuerpo colegiado en nuestra provincia data del año 1841. Este texto, al igual que el de otras provincias argentinas, estaba enmarcado por la plena soberanía de que gozaban los estados.

Sancionada la Constitución Nacional en 1853, los escritos provinciales debieron adecuarse a la misma, por así exigirlo la normativa entonces vigente.

Sin ahondar en los primeros textos de nuestra carta magna, podemos fijar como punto de partida el texto reformado en la Convención Constituyente convocada por ley en fecha 6 de diciembre de 1889.

En dicha asamblea no se procedió a modificar expresamente los artículos que podían tener connotaciones con el tema que nos ocupa. Esta reforma abarcó aspectos referidos fundamentalmente al Poder Judicial y a los municipios y comunas de la provincia.

Del análisis de su texto surge en el capítulo cuarto entre las "Atribuciones del Poder Legislativo" la ratificación del artículo $80^{\circ}$, que en su inciso 8vo. señala:

“Corresponde al Poder Legislativo las siguientes atribuciones:

$8^{0}$ - Autorizar al Poder Ejecutivo para celebrar contratos sobre empréstitos de dinero, basados en el crédito de la Provincia ú otros de utilidad pública y de carácter provincial; aprobar ó desechar los que hubiere celebrado el Poder Ejecutivo por sí, ó en virtud de la precedente autorización;"

Como se observa en el texto aludido, la autorización no establece límites, solamente concede facultades e impone para la propia legislatura el derecho de aprobar o no los empréstitos contratados por el Poder Ejecutivo.

A partir del 12 de noviembre de 1899, comienza a sesionar en Santa Fe una Convención Constituyente con el ánimo de modificar en su integridad la Carta Magna vigente. Su labor se conocerá luego como la constitución de 1900.

En la $11^{\circ}$ sesión ordinaria del día 28 de diciembre de 1899 se aprueba un nuevo texto que modifica el artículo indicado con anterioridad. Lamentablemente, como del diario de sesiones de la época se deduce, la aprobación del texto en borrador del artículo no tuvo discusión alguna por parte de los señores constituyentes, desconociéndose por lo tanto el espíritu por el cual en el nuevo texto constitucional aparece el siguiente artículo $61^{\circ}$ dentro del capítulo cuarto de "Atribuciones del Poder Legislativo":

“Corresponden al Poder Legislativo las siguientes atribuciones:

$8^{0}$ - Autorizar al Poder Ejecutivo para celebrar contratos sobre empréstitos de dinero, basados en el crédito de la Provincia, u otros de utilidad pública y de carácter provincial. Cuando versaren sobre empréstitos 0 emisión de fondos públicos, la autorización deberá ser acordada con dos tercios de votos de los miembros presentes en cada Cámara y, bajo pena de nulidad, en ningún caso el servicio de la totalidad de las deudas autorizadas y que hubieren de utilizarse podrá comprometer más de la cuarta parte de la renta provincial, tomándose como base el cálculo de recursos menor durante el quinquenio anterior a la época en que haya de concederse la autorización;"

Se observa en el nuevo texto algunos preceptos que inclusive son mejoradores en su redacción, respecto del actual. En primer lugar, tipifica espe- 
cíficamente que la autorización al Poder Ejecutivo se refiere a los empréstitos de dinero, con lo cual invalida incluir en este concepto otras situaciones que también generan un endeudamiento provincial.

En segundo lugar, fija las mayorías necesarias en cada Cámara para tomar empréstitos o fondos públicos. Estas mayorías son mucho más estrictas que las que hoy se requieren para similares situaciones.

Por último, y quizás en el tema que más nos interesa, establece que los servicios de los empréstitos utilizados, de los originariamente autorizados, no deberán superar ciertos límites. Pero además fija que el denominador que conformará la ecuación para determinar dicho valor relativo surgirá de los últimos cinco años, previos a la autorización, siendo el menor de los cálculos de recursos estipulados por la propia Legislatura.

Como se observa, con algunas imperfecciones en su redacción, el texto del año 1900 es más rico en precisiones que el actual.

La cuestionada Reforma Constituyente del año 1921, que recién fue convalidada por Ley № 2.160 del 30 de abril de 1932, y que tenía como objetivo la reforma integral de nuestra Carta Magna con excepción del artículo $4^{0}$, modificó el texto anterior quedando redactado de la siguiente manera dentro del capítulo IV del Poder Legislativo, artículo 620:

"Corresponden al Poder Legislativo las siguientes atribuciones:

$5^{0}$ - Autorizar al Poder Ejecutivo para celebrar empréstitos basados en el crédito de la Provincia. Cuando versaren sobre emisión de títulos de deuda, la autorización deberá ser acordada con dos tercios de votos en cada Cámara y, bajo pena de nulidad; en ningún caso el servicio de la totalidad de las deudas autorizadas y que hubieren de autorizarse, podrá comprometer más de la cuarta parte del promedio de los cálculos de recursos ordinarios del último quinquenio. Las leyes que autoricen la contratación de empréstitos serán dictadas en sesión especial de cada Cámara, convocada al efecto con tres días de anticipación."
Como se observa, existen algunas modificaciones sustanciales respecto del texto de 1900 . Al margen de las cuestiones de procedimientos que deben darse para aprobar las leyes pertinentes, mejora la definición de qué se entiende como empréstitos. Además, impone como componente del denominador el promedio de los últimos cinco años, lo que mejora la relación anterior que tomaba el menor cálculo de recursos del quinquenio.

Pero una modificación congruente es el reemplazo del anterior concepto de "rentas" por el de "recursos ordinarios". Esta nueva terminología que se incorpora, y que lamentablemente fue luego reemplazada, es coincidente con nuestra opinión respecto de cuáles son los parámetros lógicos que deben ser tenidos en cuenta para evaluar los niveles permitidos de endeudamiento.

Por otra parte depura de la totalidad de los recursos los concernientes solamente con su carácter ordinario, con lo cual despeja aquellos otros que se obtienen por única vez o que provienen de operaciones del uso del crédito de que goza el Estado.

Esta Constitución tuvo una vigencia efímera, porque mediante Decreto del Poder Ejecutivo del año 1935 se volvió al texto de 1900/1907.

El 25 de agosto de 1949, la Honorable Legislatura convocada por decreto $\mathrm{N}^{0} 839$ del 28 de junio del mismo año, con el objeto de adaptar la Constitución Provincial a los preceptos de la Nacional, procede nuevamente a rectificar el artículo de referencia, volviendo a la concepción básica adoptada en 1900.

En el capítulo IV "Atribuciones del Poder Legislativo", artículo $51^{\circ}$ se establece:

“Corresponden al Poder Legislativo las siguientes atribuciones:

$4^{0}$ - Autorizar al Poder Ejecutivo para celebrar contratos sobre empréstitos de dinero, basados en el crédito de la Provincia, u otros de utilidad pública y de carácter provincial. Cuando versaren sobre empréstitos 0 emisión de fondos públicos, la autorización deberá ser acordada con dos tercios de votos de los miembros presentes en cada Cámara y, bajo pena de nulidad, en ningún caso el servicio de la totalidad de 
las deudas autorizadas y que hubieren de autorizarse podrá comprometer más de la cuarta parte de la renta provincial, tomándose como base el cálculo de recursos menor durante el quinquenio anterior a la época en que haya de concederse la autorización;"

El texto precedente, excepto una sola expresión, es idéntico al de la Convención Reformadora del año 1900. Según el diario de sesiones le correspondió al legislador Albino Ferrari, por el Departamento Iriondo, señalar que con este texto "se perfecciona una sabia disposición".

Se retrocede entonces en la redacción dejando nuevamente dudas en la interpretación de ciertos términos que luego se reiteran en el texto que actualmente nos rige.

La reforma de 1949 fue anulada por proclama nacional del gobierno militar del 27 de abril de 1956 (artículo $1^{\circ}$ ) que deja sin efecto todas las constituciones provinciales del período anterior (artículo $3^{\circ}$ ) y de las nuevas provincias creadas (Chaco, La Pampa y Misiones).

Santa Fe vuelve por ello a aplicar la constitución sancionada en 1900, con carencias tales que obligaron inexorablemente a su modificación ni bien restablecido el orden institucional (1958).

Por Ley NN 5.443 del año 1961, reglamentada por Decreto No 9.443/61, se decide convocar a una Asamblea Constituyente para modificar el texto constitucional. Esta convención se reúne en 1962 y en su $7^{0}$ sesión ordinaria del día 13 de abril convalida el texto del artículo 55 inciso $12^{\circ}$ que estamos analizando.

Lamentablemente del diario de sesiones respectivo no surge discusión sobre el particular, y se desconocen los motivos de una redacción tan poco clara que hace retroceder su interpretación respecto de otras similares.

El Señor Presidente de aquella Asamblea Guillermo Chiaraviglio lee el texto del borrador propuesto que resulta votado afirmativamente por los restantes convencionales.
Para tener idea de lo maratónica de esas reuniones basta recordar que la sesión mencionada comenzó a las 17 horas y concluyó a las 7 y 40 del día 14 , y en la misma se aprobaron en particular desde el artículo $29^{\circ}$ al $116^{\circ}$.

\section{Antecedentes doctrinarios}

La redacción del actual artículo referido al tema que nos ocupa, nos obliga inexorablemente a intentar definir la terminología en él usada.

Existen al menos tres términos de los cuales es preciso dilucidar sus alcances. Ellos son por orden de importancia subjetiva: empréstitos, servicios de la deuda y rentas provinciales.

La real acepción de unos y otros es básica para poder determinar los componentes de una relación que puede significar la violación o no de un precepto constitucional, con todas las implicancias jurídicas que ello supone.

Según Oría por "crédito público puede entenderse la aptitud política, económica, jurídica y moral de un Estado para obtener dinero o bienes en préstamo, basada en la confianza de que goza por su patrimonio, los recursos de que puede disponer y su conducta" y que se traduce por el empréstito.

Como Giuliani Fonrouge señala en su libro de "Derecho Financiero" apresurémonos a decir que "la palabra empréstito debe entenderse en sentido amplio, comprensiva de las obligaciones a largo plazo (deuda consolidada; empréstito propiamente dicho) y de otras a término reducido (deuda flotante; letras o bonos de Tesorería), ya que todos participan de la misma naturaleza jurídica y sólo difieren en modalidades de realización".

La conceptualización precedente impone lograr una clasificación de los empréstitos. Según la doctrina en general, con algunas variantes que luego señalaremos, podemos incluir dentro del concepto señalado los siguientes:

a) Empréstitos de mediano y largo plazo: son las captaciones de fondos que el Estado realiza recu- 
rriendo al mercado para satisfacer sus demandas y con la promesa de su reintegro bajo determinadas formas y términos que signifiquen un beneficio para el tomador.

Por lo general se consideran de mediano plazo los que reintegran el capital recibido en plazos que van de los tres a diez años, y de largo plazo los que superan estos períodos.

b) Empréstitos a corto plazo: esta forma ordinaria de financiación se encuentra representada por tomas de dinero a través de la emisión de valores por períodos que no exceden el año. Son recursos transitorios para cubrir deficiencias estacionales de caja. Por lo general son las denominadas Letras de Tesorería que tuvieron auge en nuestra Provincia en la década del ' 70 .

También forman parte de este grupo lo que en el orden nacional se conocen como Obligaciones de Tesorería.

c) Bonos del Tesoro: dentro de los procedimientos anómalos 0 irregulares para obtener recursos al Estado, existe esta figura que consiste en la entrega a los proveedores, contratistas 0 acreedores del Estado en general de documentos que constituyen pagos diferidos en cuotas escalonadas. En este agrupamiento se incluirían los Bonos de Consolidación de Deudas tan comunes en el orden nacional.

Este último caso no difiere sustancialmente de los anteriores. La variante es que los mismos se constituyen en un empréstito forzoso en el cual los receptores de los bonos no acuden voluntariamente a suscribir los mismos.

Las características de los bonos pueden dar lugar a que algunos sean aplicados total 0 parcialmente al pago de deudas que los tomadores tengan con el propio Estado. En nuestra Provincia circularon en la década del 60 los denominados Certificados Nominativos de Compensación de Créditos que podían ser utilizados para pagar tributos a la entonces Dirección General de Rentas.

Lo que no admite discusión respecto de la categorización efectuada, es que en uno u otro caso es necesario que las emisiones estén autorizadas por el Poder Legislativo. Puede variar el modo o los tiempos de esas autorizaciones, debiendo ser expresamente una Ley, por tratarse de una facultad privativa de la Legislatura, en el primer y tercer caso; bastando para los empréstitos de corto plazo la autorización que la Ley de Presupuesto le conceda al Poder Ejecutivo y por los límites máximos en ella dispuesta.

Es necesario retomar y concretar dos conceptos que son usualmente manejados en el ámbito público. Generalmente se habla de deuda consolidada y de deuda flotante, la primera no es otra cosa que la deuda a mediano y largo plazo que es atendida anualmente mediante la autorización que se concede a un fondo de carácter permanente, mientras que la segunda es la deuda de corto plazo.

Hay autores que preferían diferenciar ambos conceptos diciendo que la primera era aquella que se encontraba "documentada" y por lo tanto tenía una certeza y grado de compromiso mayor que la otra (por ejemplo: los empréstitos con emisión de títulos). Por el contrario, la flotante era la "deuda exigible" producto de los incumplimientos financiero por parte del Estado que generaban determinados niveles de endeudamiento. Lo que no puede discutirse, y de allí lo criticable de la definición anterior, es que ambas son "escriturales o documentadas" pues en toda transacción del Estado existe previamente un acto de autoridad competente que la avala y respalda.

A la hora de definir el concepto de empréstito queda en claro que puede variar enormemente su contenido si consideramos solamente los que se traducen en la obtención de dinero por parte del Estado o si se les agrega a ellos los que son producto del diferimiento, consensuado o no de parte de los acreedores del Estado, del pago de las obligaciones asumidas.

La constitución no dice "empréstitos de dinero", como por ejemplo decían las constituciones de 1889 y 1900. Esto es sugestivo, y por ello debiera abarcar el endeudamiento que se genere a partir de recibir el Estado como contraprestación bienes o servicios.

Llevando el concepto anterior a las etapas en ma- 
teria de ejecución de las erogaciones del Estado, deberían considerarse las obligaciones devengadas y no pagadas. Es decir aquellas en que el tercero cumplió con su obligación de entregar el bien, construir la obra o prestar el servicio y el Estado no canceló la obligación emergente como consecuencia de haber pactado su diferimiento en el tiempo.

Por ello debemos hacer una importante aclaración. Si bien no se puede determinar cuál fue el espíritu que prevaleció en el ánimo de los constituyentes, se supone que en definitiva lo que se persigue con esta normativa es fijar límites al endeudamiento.

Lo que se pretende es que el compromiso que deban asumir los presupuestos futuros (o las generaciones futuras si hablamos de empréstitos de más largo plazo) no conlleven a embargar en demasía los recursos ordinarios e impidan con ello satisfacer las necesidades y demandas corrientes que presupone el desarrollo de la gestión anual de un gobierno.

La cuestión en este punto radica en atarse al texto literal de la constitución o especular sobre un ámbito mayor que interprete el silogismo que una limitante impone al poder administrador.

Preferimos quizás aventurar cual es la exigencia máxima que se le obliga a respetar al Poder Ejecutivo, a caer en una violación arbitraria del texto constitucional.

El segundo de los conceptos a analizar es el que hace a "servicios de la deuda". Por lógica consecuencia, y atendiendo estrictamente a lo señalado en el artículo 550 de nuestra Constitución, este término esta condicionado a lo que entendamos por empréstitos.

El artículo dice "el servicio de la totalidad de las deudas provenientes de empréstitos", con lo cual es importante y definitorio fijar los componentes adecuados. Lo que pareciera que está claro es que la palabra "servicios" involucra varios conceptos:

- amortización del capital: que es el reembolso de la suma prestada.

- intereses: comprende la retribución del capital prestado.

- ajustes del capital: son reconocimientos, casi siempre de carácter financieros, efectuados en los empréstitos conocidos como "indizados", pues tienen como fin neutralizar las variaciones monetarias a través de valores referidos a números-índices 0 precios 0 cotizaciones de ciertos bienes (inclusive monedas de otros países). En nuestro léxico podemos asociarlo con el término "actualizaciones".

- comisiones de compromiso: este gasto por la no utilización de los créditos disponibles es un novísimo concepto que constituye un costo para el Estado y que debe ser tenido en cuenta.

Queda por ver si dentro de los conceptos anteriores se involucran los importes que devienen de la morosidad 0 incumplimiento de las obligaciones en tiempo y forma de parte del Estado. Si consideramos el criterio genérico de que lo accesorio sigue a lo principal, tales obligaciones deben ser imputadas al mismo ítem de servicios de la deuda.

Otro concepto que puede ser evaluado entre los precedentes, es el referido a los gastos necesarios para la constitución del empréstito. Se entendería que estos son previos a la generación del endeudamiento y por lo tanto no formarían parte del "servicio" necesario para su cancelación. Es más, en muchas situaciones tales erogaciones, referidas a gastos de promoción del empréstito a tomar, pueden culminar con la no suscripción del mismo, por lo que ello debiera quedar excluido de la relación que pretendemos clarificar.

Resta conceptualizar el término "renta provincial". De hecho que como lo dijimos en oportunidad de expresarnos con los alcances de "empréstito", si utilizamos un concepto restringido achicará el denominador de la ecuación y con ello elevará las posibilidades de acercarse o sobrepasar la limitante constitucional. Si por el contrario el término es amplio, alejará el peligro de superar el cuarto establecido de las mismas como límite de los servicios a cubrir en el ejercicio.

La Carta Magna no hace distingos que se compatibilicen con la organización institucional del Estado provincial. Es más, difícilmente a los con- 
vencionales constituyentes les haya interesado, al momento de legislar sobre este texto, la anárquica situación que plantea la estructura presupuestaria provincial, separando una Administración pública provincial (Poderes Ejecutivo, Legislativo y Judicial, cuentas especiales, organismos descentralizados e instituciones de la seguridad social) del resto de las empresas, sociedades y entidades financieras.

Esta desagregación entre entes que consolidan 0 no sus estados presupuestarios (y por ende de ejecución) conspira contra la posibilidad de contar con un sector público integrado y con ello conocer los reales importes que corresponden al tema que nos ocupa.

Por ello, debe interpretarse que la intención de los constituyentes fue tomar a la provincia como un conjunto integrador y medir sus niveles de deudas en sentido general y totalizador.

Al considerar, por lo tanto, que la renta es del conjunto del Estado y no de una parte de él, generada por la totalidad del mismo y no solamente por algún ente u organismo, se hace necesario precisar qué se entiende por ella.

También aquí debemos reinterpretar la intención que los Constituyentes tuvieron respecto de este término.

El concepto tradicional de "renta" como retribución de uno de los factores básicos del ciclo productivo, cual es la tierra, no es el carácter que se le pretendió dar.

Con este término se pretende agrupar el conjunto de recursos de que el Estado dispone con prescindencia de los que provienen del endeudamiento 0 incremento de pasivos. Es decir, sólo deben incluirse los recursos ordinarios que revisten las características de habituales 0 son originados en fuentes permanentes de generación de ingresos al Estado.

Para adaptarlo a la estructura presupuestaria actual, de un consolidado del sector público provincial, habría que despejar los rubros que hacen a las fuentes de financiamiento, ya sea el uso del crédito (otorgado por instituciones bancarias o financieras o por los propios proveedores y contratistas del Estado) y los aportes reintegrables que reciba del
Gobierno Nacional o de otros estamentos públicos, semipúblicos o privados.

No corresponde la inclusión como recurso ordinario del Estado los denominados Ingresos o Recursos de Capital, que provienen de la venta de activos fijos (disminución de la inversión real) o los reembolsos de préstamos concedidos oportunamente.

La inclusión de recursos afectados en su origen es muy discutible, si atendemos a las características y destino de los mismos. Quizás debieran solamente considerarse para la ecuación aquellos que siendo afectados lo son a los efectos de ser destinados a cancelar créditos generados por endeudamiento del Estado.

Sólo podemos tener una idea de la magnitud de una cosa comparándola con otra. Por ello se limita constitucionalmente a comprometer hasta un cuarto de la renta provincial.

Lo contrario a determinar la real carga de la deuda que se debe soportar, es intentar medir la capacidad de endeudamiento. Como ello no es posible, fundamentalmente por carecer el Estado de la real dimensión de su patrimonio, no hay otra alternativa que mensurar las obligaciones asumidas.

\section{Reglamentación y aplicación del texto constitucional}

Con la sanción de la Ley provincial Nro. 12.510 denominada "Ley de Administración, Eficiencia y Control" se procede a legislar entre los distintos sistemas de administración financiera del Estado lo concerniente con el crédito público.

En el título II, capítulo III, sección II en donde se establecen las Normas Técnicas Comunes, en su artículo $60^{\circ}$ se determinan cuales son las operaciones generadoras del endeudamiento del Estado provincial.

Dice el mismo: "El endeudamiento que resulte de las operaciones de crédito público se denomina deuda pública provincial y puede originarse en: 
a) La emisión y colocación de títulos, bonos u obligaciones de largo y mediano plazo, constitutivos de un empréstito;

b) La emisión y colocación de letras de Tesorería y la emisión de pagarés u otros medios sucedáneos de pago, cuyo vencimiento supere el ejercicio financiero;

c) La contratación de préstamos con instituciones financieras nacionales, extranjeras o internacionales; u otras instituciones u organismos que tengan facultad para realizar estas operaciones;

d) La contratación de obras, servicios o bienes cuyo pago total o parcial se estipule realizar en el transcurso de más de un ejercicio financiero posterior al vigente; siempre y cuando los conceptos que se financien se hayan devengado anteriormente $y$ documentado a través de los medios de pago o financiamiento que se establecen en los incisos a), b), o c) del presente artículo;

e) El otorgamiento de avales, fianzas y garantías, cuyo vencimiento supere el período del ejercicio financiero; la que no se considerará a los efectos del cómputo del Artículo 70;

f) La consolidación, conversión y renegociación de deudas.

No se considera deuda pública provincial:

- La deuda del Tesoro, entendida ésta como las obligaciones devengadas y no pagadas durante el ejercicio;

- La emisión de letras, pagarés u otros medios sucedáneos de pago cuando se cancelen dentro del ejercicio."

Del análisis de este texto se deduce que los "servicios de la deuda" deben obedecer a conceptos generados por los instrumentos o medios mencionados en este artículo.

Podría considerarse que la deuda presupuestaria exigible, generada por incumplimientos de obligaciones asumidas por el Estado, pueda quedar excluida de los coeficientes necesarios para cumplir con el artículo constitucional, siempre y cuando los mismos no hayan sido pactados con específico dife- rimiento a futuros ejercicios, en cuyo caso sí serían componentes del numerador, como bien dice el artículo transcripto.

Este tema es muy discutible y podemos encontrar en la jurisprudencia dos tendencias. Por un lado, la nacional cuya Ley de Administración y Control Nro. 24.156 la excluye expresamente. El artículo $57^{\circ}$ de la mencionada Ley establece que "...no se considera deuda pública la deuda del Tesoro..."

Por su parte, el decreto Nro. 1364 del Estado provincial dictado el 5 de junio de 2001, y que reglamenta el modo de determinar los parámetros de endeudamiento de los municipios y comunas de la provincia fijados en sus leyes orgánicas, incorpora como causal del endeudamiento a estos conceptos. A tal fin el artículo $2^{0}$ inciso g) establece que deberá incluirse "...el promedio de los últimos tres ejercicios financieros cerrados de la deuda, neta de disponibilidades sin afectación, del tesoro municipal o comunal, entendida como las obligaciones devengadas y no pagadas al cierre del ejercicio financiero anterior que surge como producto de obligaciones generadas a partir de la recepción o contratación de bienes, servicios u obras, como contraprestación, y también, a partir de obligaciones que surgen de la ley sin contraprestaciones ...".

No obstante el antecedente anterior, y por motivos que exceden con creces este trabajo,y que pasa por las metodologías de apropiación de los recursos y gastos y sistemas para determinar los resultados económicos y financieros en el sector público, es criterio que este tipo de deuda no debe incluirse en el numerador pertinente para determinar el coeficiente de endeudamiento como bien lo señala la Ley № 12.510 .

La segunda conclusión es que para medir el grado de compromiso que pueden tener los futuros recursos del Estado, no sólo basta con verificar las efectivas contingencias pactadas y sus consecuentes servicios, sino que hay que determinar las potenciales situaciones derivadas de avales, fianzas y garantías en donde el Estado puede convertirse en deudor principal ante el incumplimiento de los 
directamente involucrados en la negociación. Lamentablemente, la Ley Provincial Nro. 12.510 excluye estos conceptos en el momento de determinar el volumen de la deuda provincial.

Además, no escapan a estas consideraciones, los modernos sistemas de endeudamiento aparecidos en el Estado en los últimos años, como por ejemplo los que devienen de la constitución de fondos fiduciarios, integrados total o mayoritariamente con bienes y/o fondos de los distintos Estados. Los mismos generan un pasivo cuyo rescate debe también conformar el "servicio" requerido por la Constitución.

Pero la Ley Nro. 12.510 va mucho más allá y en su sección III procede a reglamentar el tan controvertido artículo $55^{\circ}$ inciso 12) de la Constitución Provincial.

Legisla en su artículo 70: "Se entiende como 'servicio de la totalidad de las deudas provenientes de empréstitos' a la sumatoria de la amortización del capital, interés, eventuales actualizaciones del capital, comisiones y todo otro cargo proveniente del endeudamiento contraído en el marco de esta ley.

Se consideran incluidos en el concepto precedente los servicios provenientes de deudas similares contraídas con anterioridad a la vigencia de esta ley.

Se entiende a los fines del Artículo 550, Inciso 12) de la Constitución Provincial, la relación existente al cierre del ejercicio financiero anterior entre los conceptos involucrados en el primer párrafo y el conjunto de los recursos recaudados, excluidos los de afectación específica, los de capital y los obtenidos del financiamiento, de la totalidad de la Administración Provincial."

En definitiva, queda en claro cuales son los componentes del numerador y del denominador exigidos por la Constitución Provincial para determinar los límites del endeudamiento.

Lo extraño de todo esto es que, contradiciendo la postura que sustentamos en párrafos anteriores, sólo considera en el numerador y en el denominador los servicios y los recursos de la "Administración Provincial", es decir, que deja de lado en la determinación del coeficiente constitucional los provenien- tes de las sociedades, empresas y otros entes públicos (Empresa Provincial de la Energía, Laboratorio Productos de Fármacos Medicinales, Aguas Santafesinas S.A., Túnel Subfluvial "Uranga-Sylvestre Begnis", etc.) que se encuentran categorizados como tal en el artículo $4^{0}$ de la Ley Nro. 12.510.

Es decir, vuelve a considerar los límites del endeudamiento de sólo una parte del sector público, como si el resto no formara parte de él y no comprometiese de igual modo las finanzas provinciales.

Con relación al momento en que debe cuantificarse el cociente de referencia, los servicios de un ejercicio deben confrontarse con los recursos recaudados al cierre del ejercicio anterior, evitando con ello determinar un potencial y optimista denominador que puede no darse en la realidad. Por supuesto que en períodos de constante envilecimiento del signo monetario ello se efectuaría a valores homogéneos.

\section{Controversias ante la san- ción de la ley nacional Nro. 25.917}

El 4 de agosto de 2004 se sanciona en el orden nacional la Ley Nro. 25.917 denominada "Régimen Federal de Responsabilidad Fiscal" que entre las múltiples reglas que establece con el objeto de mejorar el comportamiento fiscal y dotar de una mayor transparencia a la gestión pública, incorpora un capítulo V referido al "Endeudamiento".

En su artículo $21^{\circ}$ señala: "Los gobiernos de las provincias y de la Ciudad Autónoma de Buenos Aires tomarán las medidas necesarias para que el nivel de endeudamiento de sus jurisdicciones sea tal que en cada ejercicio fiscal los servicios de la deuda instrumentada no superen el quince por ciento (15\%) de los recursos corrientes netos de transferencias por coparticipación a municipios.

Las jurisdicciones, en el marco de la presente ley, establecerán un programa de transición con el objeto de adecuar el perfil de la deuda y los instrumentos para el cumplimiento del párrafo precedente. 
El Gobierno nacional se compromete a que, una vez finalizado el proceso de reestructuración de su deuda pública, el porcentaje de la deuda pública nacional resultante de operaciones de mercado, respecto del Producto Bruto Interno, se reduzca en los ejercicios fiscales subsiguientes. A tales fines se considerarán períodos trienales.

En caso de operaciones de crédito público para reestructurar la deuda pública, será de aplicación el artículo 65 de la ley $n^{0} 24.156$ de Administración Financiera y Sistemas de Control del Sector Público Nacional.

Los Gobiernos de las provincias y la Ciudad Autónoma de Buenos Aires se comprometen a no emitir títulos sustitutos de la moneda nacional de curso legal en todo el territorio del país."

Por su parte el artículo siguiente agrega: "AqueIlas jurisdicciones que superen el porcentaje citado en el artículo anterior no podrán acceder a un nuevo endeudamiento, excepto que constituya un refinanciamiento del existente y en la medida en que tal refinanciación resulte un mejoramiento de las condiciones pactadas en materia de monto, plazo y/o tasa de interés aplicable, y/o los financiamientos provenientes de Organismos Multilaterales de Crédito y de programas nacionales, en todos los casos sustentados en una programación financiera que garantice la atención de los servicios pertinentes."

Si bien la ley continúa luego en los restantes artículos estableciendo metodologías que deben seguirse para que las provincias se endeuden y tratamiento presupuestario a otorgar a las mismas, el conflicto se centra sobre los artículos transcriptos.

La pregunta que surge es: ipuede al Estado Nacional a través de una ley otorgar límites distintos a los que establecen cada una de las constituciones provinciales en el mismo tema?

De hecho que tal controversia no será motivo de discusión hasta que los porcentajes indicados en una 0 en otra norma no sean necesarios de calcular y determinar sí se esta por encima o por debajo de ellos.

En principio señalemos que esta ley nacional mereció una frondosa reglamentación, entre las cuales se destaca el decreto nacional Nro. 1.731/04 que determina que el cálculo establecido por el artículo $21^{\circ}$ de la ley se determina para las Administraciones públicas no financieras, es decir, al igual que la reglamentación constitucional provincial deja afuera a las sociedades, empresas y otros entes públicos.

Vemos luego que los porcentajes exigidos son distintos: 25 \% la Constitución Provincial y $15 \%$ la Ley Nacional.

Los conceptos de servicios tampoco son equivalentes. La reglamentación establecida por la ley Nro. 12.510 determina que se trata de la sumatoria de la amortización del capital, interés, eventuales actualizaciones del capital, comisiones y todo otro cargo proveniente del endeudamiento contraído en el marco de esta ley. Por su parte la reglamentación de la ley nacional establece que son los gastos destinados a atender el pago por intereses, amortizaciones y comisiones derivadas del endeudamiento.

Por último los conceptos componentes del denominador también son distintos. La ley provincial Nro. 12.510 establece que se considerará el conjunto de los recursos recaudados, excluidos los de afectación específica, los de capital y los obtenidos del financiamiento. En cambio la ley nacional establece que se tomarán los recursos corrientes netos de transferencias por coparticipación a municipios.

¿Cuál norma prevalece? ¿Cómo se concilian dos normas que adolecen de tantas diferencias? ¿Se ha producido un avasallamiento de los preceptos constitucionales provinciales?

Para los que sostienen que prevalece la norma nacional se basan en que la misma se sancionó dentro de los términos del artículo $31^{\circ}$ de la Constitución Nacional que dice que "esta Constitución, las leyes de la Nación que en su consecuencia se dicten por el Congreso y los tratados con las potencias extranjeras son la Ley suprema de la Nación; y las autoridades de cada provincia están obligados a conformarse a ella, no obstante cualquiera disposición en contrario que contengan las leyes o constituciones provinciales..."

Además sostienen que puede interpretarse que la 
misma es transicional y por ello debe ser acatada por las provincias.

Argumentan por último, que en el caso de la Provincia de Santa Fe la Ley Provincial Nro. 12.402 por la cual se adhirió a la Ley Nacional Nro. 25.917, prevé que la adhesión no implica cercenamiento ni disminución de las potestades o prerrogativas contempladas en la Constitución Provincial. Por ello es viable la aplicación de este articulado.

Por el contrario quienes están en la posición enfrentada, sostienen que esta ley nacional no fue sancionada en consecuencia de los términos constitucionales nacionales como establece el artículo $31^{\circ}$ de la Carta Magna; y que sí se hizo violando el artículo $121^{\circ}$ de la Constitución Nacional por ser la materia en ella tratada facultad exclusiva de los gobiernos provinciales, no delegada al Estado Nacional.

Lo cierto es que las diferencias de interpretación pueden en algún momento suscitar controversias que serán apoyadas por unos u otros según convenga la crítica o el halago al gobierno de turno.

Sería prudente consensuar posturas ahora y no esperar el estallido de un conflicto de intereses cuando sea necesario determinar el nivel del endeudamiento provincial. 